\title{
The Use of the lodine-Rich Drug Amiodarone in the Rapid Preoperative Preparation for Thyroidectomy because of Persistent Hyperthyroidism
}

\author{
Christiaan F. Mooij $^{a} \quad$ Nitash Zwaveling-Soonawala ${ }^{a}$ Eric Fliers ${ }^{b}$ \\ A.S. Paul van Trotsenburga \\ a Department of Pediatric Endocrinology, Emma Children's Hospital, Amsterdam UMC, University of \\ Amsterdam, Amsterdam, The Netherlands; ' Department of Endocrinology and Metabolism, Amsterdam UMC, \\ University of Amsterdam, Amsterdam, The Netherlands
}

Dear Editor,

Hyperthyroidism due to Graves' disease is primarily treated with antithyroid drugs. Thyroidectomy is mostly considered to provide definitive therapy in case of recurrent or persistent hyperthyroidism. However, carrying out this procedure during hyperthyroidism may result in thyroid storm or a thyrotoxic crisis, conditions known for their high morbidity and mortality. To prevent this during or following thyroidectomy, preoperative preparation to reach euthyroidism is essential.

According to current guidelines, preoperative treatment of (refractory) hyperthyroidism consists of the administration of a thionamide (e.g., methimazole), betablocker, glucocorticoid, and an iodinecontaining preparation [1]. These treatment protocols are based on blocking thyroid hormone synthesis and secretion (by thionamides and iodine-containing preparations [acute Wolff-Chaikoff effect]); inhibition of peripheral conversion of the biologically inactive prohormone thyroxine (T4) to active triiodothyronine (T3) (by beta-blockers, glucocorticoids, and iodinecontaining preparations); and attenuating the peripheral action of thyroid hormones (by beta-blockers). So far, the use of several iodine-containing preparations has been described in the preoperative preparation of thyrotoxic patients: Lugol's solution, potassium iodide, and iopanoic acid [2-4]. Panzer et al. [3] reported an average duration of 7 days of preoperative preparation with iopanoic acid, dexamethasone, and methimazole or propylthiouracil before thyroidectomy in 17 Graves' disease patients. Fischli et al. [2] reported that, after 10 days of preoperative preparation with Lugol's solution, dexamethasone, and a beta-blocker, 8 out of the 10 studied patients had normal FT3 levels, while the other 2 patients reached normalization of FT3 only after 14 days of treatment.

However, the use of amiodarone, an antiarrhythmic drug containing a high concentration of iodine, has not been described previously in the preoperative treatment of (pediatric) hyperthyroid patients scheduled for thyroidectomy. Amiodarone is known for side effects such as transient or permanent hypothyroidism or thyrotoxicosis [5-7]. Besides acute blocking of thyroid hormone synthesis by its high iodine content (the mechanism behind the transient hypothyroidism), preoperative treatment with amiodarone may restore (tissue) euthyroidism also via two other mechanisms: (1) inhibition of T4 to T3 conversion, and (2) inhibition of binding of thyroid hormone to thyroid hormone receptor beta 1 by the metabolite desethylamiodarone [5]. Therefore, amiodarone is a potential drug to use in the rapid preoperative preparation of hyperthyroidism. An argument against using amiodarone for this purpose is the risk of inducing hyperthyroidism later on. Since the thyroid gland is surgically removed shortly after amiodarone is started, this is not a risk in this context.

Because of thionamide-resistant Graves' hyperthyroidism, most probably due to poor compliance, a 17-year-old girl consented to total thyroidectomy as definitive treatment. The girl was admitted to our pediatric surgical ward 4 days prior to surgery for rapid preoperative preparation. The treatment regimen consisted of high-dose thionamide (propylthiouracil $200 \mathrm{mg}$ six times per day); a beta-blocker (propranolol $80 \mathrm{mg}$ three times per day); a glucocorticoid (hydrocortisone $100 \mathrm{mg}$ three times per day); and an iodine-containing preparation (amiodarone $200 \mathrm{mg}$ twice daily). The patient consented to this experimental rapid

\section{KARGER}

E-Mail karger@karger.com www.karger.com/etj

\section{(C) 2019 The Author(s)}

Published by S. Karger AG, Basel

Karger
Open access

This article is licensed under the Creative Commons AttributionNonCommercial-NoDerivatives 4.0 International License (CC BYNC-ND) (http://www.karger.com/Services/OpenAccessLicense) Usage and distribution for commercial purposes as well as any distribution of modified material requires written permission.
Christiaan F. Mooij, MD, $\mathrm{PhD}$

Department of Pediatric Endocrinology, Emma Children's Hospital Amsterdam UMC, University of Amsterdam, Meibergdreef 9

NL-1105 AZ Amsterdam (The Netherlands)

E-Mail c.f.mooij@amc.uva.nl 
Table 1. Biochemical evaluation of thyroid hormone and TSH levels during rapid preoperative preparation and directly after thyroidectomy in a 17-year-old girl with medical treatment-resistant Graves' hyperthyroidism

\begin{tabular}{llcc}
\hline & T3 (nmol/L) & FT4 (pmol/L) & TSH (mU/L) \\
\hline Day 0 - before start of preoperative preparation & 7.60 & $>70.0$ & $<0.01$ \\
Day 1 & 4.00 & $>70.0$ & $<0.01$ \\
Day 2 & 2.25 & $>70.0$ & $<0.01$ \\
Day 3 & 2.00 & 67.9 & $<0.01$ \\
Day 5 (1 day after thyroidectomy) & 1.15 & $>70.0$ & $<0.01$ \\
Day 8 (4 days after thyroidectomy) & 1.70 & 30.1 & $<0.01$ \\
Day 10 (6 days after thyroidectomy) & 1.60 & 21.2 & $<0.01$ \\
Local reference values & $1.30-2.70$ & $10-23$ & $0.50-5.00$ \\
\hline
\end{tabular}

preoperative preparation after being informed about potential side effects of all used drugs. This preoperative treatment regimen was previously used successfully in adult hyperthyroid patients undergoing thyroidectomy in our center. The treatment goal was to achieve a normal plasma T3 concentration just before surgery. Biochemical analysis was performed to evaluate the effect of treatment (Table 1). Normal T3 concentrations were reached within 2 days after initiation of treatment. After thyroidectomy, performed on day 4 , treatment with propylthiouracil, hydrocortisone, and amiodarone was stopped. Propranolol was

\section{References}

1 Kahaly GJ, Bartalena L, Hegedüs L, Leenhardt L, Poppe K, Pearce SH. 2018 European Thyroid Association Guideline for the Management of Graves' Hyperthyroidism. Eur Thyroid J. 2018 Aug;7(4):167-86.

2 Fischli S, Lucchini B, Müller W, Slahor L, Henzen C. Rapid preoperative blockage of thyroid hormone production/secretion in patients with Graves' disease. Swiss Med Wkly. 2016 Jan;146:w14243. continued until free T4 was normal, and levothyroxine treatment was started. Since amiodarone treatment is associated with a prolonged QTc time, hypotension and hepatic impairment, the girl underwent cardiac evaluation (including electrocardiograms) and monitoring of blood pressure and liver enzymes before and during the preoperative preparation. No side effects were seen, which was not unexpected since side effects of amiodarone are only seen after a longer duration of treatment.

This case illustrates that iodine-rich amiodarone can be used in the rapid preoperative preparation for thyroidectomy in hyperthyroid patients. It is hard to quantify the isolated effect of amiodarone in reaching euthyroidism, as it was used in combination with other drugs. Nevertheless, amiodarone may be more effective in restoring euthyroidism than the aforementioned preparations because it acts via three different mechanisms.

\section{Disclosure Statement}

The authors have no conflicts of interest, and no competing financial interests exist.
3 Panzer C, Beazley R, Braverman L. Rapid preoperative preparation for severe hyperthyroid Graves' disease. J Clin Endocrinol Metab. 2004 May;89(5):2142-4.

4 Berghout A, Wiersinga WM, Brummelkamp WH. Sodium ipodate in the preparation of Graves' hyperthyroid patients for thyroidectomy. Horm Res. 1989;31(5-6):256-60.

5 Bogazzi F, Tomisti L, Bartalena L, AghiniLombardi F, Martino E. Amiodarone and the thyroid: a 2012 update. J Endocrinol Invest. 2012 Mar;35(3):340-8.
6 Costigan DC, Holland FJ, Daneman D, Hesslein PS, Vogel M, Ellis G. Amiodarone therapy effects on childhood thyroid function. Pediatrics. 1986 May;77(5):703-8.

7 Bartalena L, Bogazzi F, Chiovato L, Hubalewska-Dydejczyk A, Links TP, Vanderpump M. 2018 European Thyroid Association (ETA) Guidelines for the Management of Amiodarone-Associated Thyroid Dysfunction. Eur Thyroid J. 2018 Mar;7(2):55-66. 